\title{
BMJ Global Health Primary care financing: a systematic assessment of research priorities in low- and middle-income countries
}

Felicity Goodyear-Smith, ${ }^{\oplus}$ Andrew Bazemore, ${ }^{2}$ Megan Coffman, ${ }^{2}$ Richard Fortier, ${ }^{1}$ Amanda Howe, ${ }^{3}$ Michael Kidd, ${ }^{4,5}$ Robert Phillips, ${ }^{6}$ Katherine Rouleau, ${ }^{\circ}$ Chris van Weel ${ }^{\odot 7,8}$

To cite: Goodyear-Smith F, Bazemore A, Coffman M, et al. Primary care financing: a systematic assessment of research priorities in low- and middle-income countries. BMJ Glob Health 2019;4:e001483. doi:10.1136/ bmjgh-2019-001483

Handling editor Seye Abimbola

- Additional material is published online only. To view please visit the journal online (http://dx.doi.org/10.1136/ bmjgh-2019-001483).

Received 6 February 2019 Revised 29 March 2019 Accepted 30 March 2019

\section{Check for updates}

(C) Author(s) (or their employer(s)) 2018. Re-use permitted under CC BY-NC. No commercial re-use. See rights and permissions. Published by BMJ.

For numbered affiliations see end of article.

\section{Correspondence to} Felicity Goodyear-Smith; f.goodyear-smith@auckland. ac.nz

\section{ABSTRACT}

Introduction Financing of primary healthcare $(\mathrm{PHC})$ is the key to the provision of equitable universal care. We aimed to identify and prioritise the perceived needs of PHC practitioners and researchers for new research in low- and middle-income countries (LMIC) about financing of PHC. Methods Three-round expert panel consultation using web-based surveys of LMIC PHC practitioners, academics and policy-makers sampled from global networks. Iterative literature review conducted in parallel. First round (PreDelphi survey) elicited possible research questions to address knowledge gaps about financing. Responses were independently coded, collapsed and synthesised to two lists of questions. Round 2 (Delphi Round 1) invited panellists to rate importance of each question. In Round 3 (Delphi Round 2), panellists ranked questions in order of importance.

Results A diverse range of $\mathrm{PHC}$ practitioners, academics and policy-makers in LMIC representing all global regions identified 479 knowledge gaps as potentially critical to improving PHC financing. Round 2 provided 31 synthesised questions on financing for rating. The top 16 were ranked in Round $3 e$ to produce four prioritised research questions. Conclusions This novel exercise created an expansive and prioritised list of critical knowledge gaps in PHC financing research questions. This offers valuable guidance to global supporters of primary care evaluation and implementation, including research funders and academics seeking research priorities. The source and context specificity of this research, informed by LMIC practitioners and academics on a global and local basis, should increase the likelihood of local relevance and eventual success in implementing the findings.

\section{INTRODUCTION}

In 1978, the Declaration signed at Alma-Ata labelled primary healthcare (PHC) the central function and main focus (of a) country's health system, calling for it to be strengthened, particularly in low- and middle-income countries (LMIC). ${ }^{1}$ It is important to differentiate $\mathrm{PHC}$ from primary care (PC) which is a discrete set of health services which are essential to delivering PHC, which comprises wider,

\section{Key questions}

What is already known?

- Financing of primary healthcare (PHC) has to be integrated in countries' socio-economic and political conditions, and must drive health systems to invest in, and incentivise, best use of PHC

- PHC is essential for access for all to affordable high-quality healthcare (universal health coverage).

What are the new findings?

- There is a marked deficiency in studies providing country context-specific evidence of financing PHC in low- and middle-income countries (LMIC).

What do the new findings imply?

- Policy-makers and non-governmental organisations in LMIC should address these evidence needs and engage with PHC professionals and other stakeholders in implementing PHC.

- Political support is needed for research to inform and align with country-level developments for stronger PHC.

multisectoral functions that include community services and public health. Timely access to affordable, acceptable PC from competent providers is crucial to achieving prevention, diagnosis, treatment and ongoing management of health problems. ${ }^{2-6}$ Robust PC, able to assume responsibility for integrating and addressing multiple care needs, is key to doing this in a cost-effective and proactive way that maximises patient empowerment and also addresses population health needs. ${ }^{7} \mathrm{PC}$ and PHC share the need for attention to investment in a well-trained and well-resourced workforce which is adequate and appropriate for specific regional and national contexts, and the infrastructure to allow them to deliver effective care across the life cycle. The World Bank, Organisation for Economic Co-operation and Development (OECD) and Bill \& Melinda Gates Foundation have produced a 
paper quantifying PC spend across developed countries, finding that for the 24 countries analysed, 'spending for primary care averages around $12 \%$ of current health spending, ${ }^{8}$ This requires a shared understanding of how $\mathrm{PC}$ is financed or otherwise resourced, to contribute to the PHC functions that produce equity and value across health systems. In this study, we refer to PC rather than PHC.

Much of the initial response to Alma Ata was the introduction of vertical programmes for specific populations and diseases, ${ }^{9}$ but contemporary PC is now expected to give access to range of services spanning health promotion, prevention, acute and chronic care management, palliative care and rehabilitation for the whole population, and often involving multidisciplinary teams. ${ }^{10}$ Services should be 'people-focused' and community-based 'horizontal' services (providing comprehensive care) for both individuals and families, acting as the first point of care and maximising health gain. ${ }^{11}$ The original Declaration recognised that key factors in its effectiveness would be individual and community engagement in PHC organisation. ${ }^{1}$ In its closing sentences, the Declaration called on the "whole world community to support national and international commitment to primary healthcare and to channel increased technical and financial support to it, particularly in developing countries'. Over the subsequent 40 years, most PHC research has been hosted by, and focused on high-income nations, and this research typically focused more narrowly on PC. Even among wealthy nations, the majority of research funding has been bioscience and treatment focused, with scant research attending differences in population health outcomes associated with different financing models for PC. The importance of investment in PC and PHC research often has been poorly recognised. ${ }^{12}{ }^{13}$ There remains a need to synthesise and extend the evidence about how to measure PHC financing; what levels of financing are associated with better outcomes; and to learn with LMICs about how they might inform new approaches and implementation research on PHC, and particularly PC, financing.

There is a global move to enable assessment of PHC financing and associated outcomes. There is also an expectation that accurate data can be provided to support international comparison of PHC financing, and research to provide evidence on better models, ${ }^{8}$ noting that no sector in a health system-or any civil societycan maximise its outputs if other parts are weak.

Within this broad context, there is a need to engage directly with those who are at the frontline of both clinical and academic delivery in LMICs. Direct engagement with the PC sector to identify gaps in research is critical if we are to ensure that their experience and expertise on current models, key changes and market factors are identified. Aware of the underinvestment to date in the PHC academic capability of many LMICs, the research team hosting this study also wanted to explore the ability of participants to act as collaborators for future studies.
In doing so, we expected to find that, while there will be common underlying principles, different settings may need different models of care with different financing needs. For example, planners in high-income countries (HICs) may have greater access to the resources required to secure robust PHC teams than in areas with fewer existing resources. Focusing on PC investment prioritisation, we hypothesise that, at least at the first stage of PHC prioritisation, a different care model might, for example, put resources into a local team supported by investments in telehealth and air evacuation for acute conditions. Also, a region such as sub-Saharan Africa with many LMICs and a low ratio of trained PC workforce members for the population has historically relied on non-governmental organisations (NGOs) as well as government funding; so innovative models that bring both sectors together to co-deliver new developments and equitable coverage in PHC may be appropriate.

Adequate financing of PHC and PC is key to the provision of equitable universal care. This includes the need to better understand how public-private providers (PPPs) in LMICs may enhance or impede quality of care, and how PPP might be leveraged to enable scaling to provide services: particularly for healthcare accessibility for populations isolated by poverty, gender, rurality and/or other dimensions of inequity. ${ }^{7}$ Per capita spending for a health system does not necessarily equate with quality and safety, but an international benchmark of the minimum spend ratio of PC to secondary and tertiary care is being debated. ${ }^{14}$ Finance and other resourcing is a challenge, but finding a balance between sustainable models for universal health coverage and ensuring maximised quality and access is challenging.

In 2017, the Primary Healthcare Performance Initiative (PHCPI) of the World Bank, Gates Foundation and WHO developed a conceptual framework of the five domains of highly functioning PHC: system, inputs, service delivery processes, outputs, and outcomes. ${ }^{15}$ Financing and outputs for cost are part of this prioritisation agenda.

The aim of this study is to address the PHCPI priority innovation area of financing (market structure, political economy and uptake of evidence). To do so, we need to identify and prioritise the knowledge needs of PHC practitioners, researchers and policy-makers in LMIC, leverage on the work conducted by the Primary Healthcare Measurement \& Implementation Research Consortium, and further informed by a scoping literature review.

Objectives:

1. Produce a list of 16 prioritised research questions relevant to the needs for evidence on PHC in LMIC.

2. Produce a 'gap map', analysing areas where there is existing evidence for questions perceived to be knowledge gaps, and where there are major gaps in evidence regarding questions about PHC financing.

3. Prepare research implementation plans for the top three research questions identified. 


\section{METHODS}

\section{Development of prioritised research questions}

Stakeholder engagement

Prior work confirms that the successful engagement of PHC providers in research enquiries requires fostering the belief that the project outputs will be helpful to their constituency in terms of progressing efficient use of time and resources, clear conceptual and linguistic communication, and trust in the agency making the enquiry. ${ }^{16}$ This is aligned with evidence about how to empower other stakeholders such as patients-that there should be 'nothing about me without me'. ${ }^{17}$ This is essential to engage academic and clinical staff working in PHC sectors, who understand the context of their own settings. ${ }^{15}$ For this study, we drew on our extensive collective networks, including World Organisation of Family Doctors (WONCA), Robert Graham Centre, the American Board of Family Medicine and the Canadian Besrour Centre. We also enlisted the support of Primafamed (an institutional network of family physicians, health professionals, academics and researchers in sub-Saharan Africa), The North American Primary Care Research Group, the South Pacific Community Global Health at the School of Population Health, University of Auckland and the International Council of Nurses to invite participants into the study. Furthermore, we specifically targeted rural networks, including WONCA's extensive Rural Working Party on Research, recognising that the rural voice is essential, and that rural communities are often neglected in global discussions. We allowed onward networking from initial contacts, although the respondents in other communities were relatively few.

\section{Study design}

We used a modified Delphi panel of PHC experts from LMIC. This is an iterative technique in which sequential surveys are answered anonymously by a range of relevant experts, with summarised feedback to enable reaching a consensus. ${ }^{18}$ We identified LMIC from the World Bank list of economies. ${ }^{19}$ We aimed for a diverse sample, with representation from LMIC in each of the following six regions: Africa, Asia/Pacific, South Asia, Latin America and the Caribbean, Eastern Mediterranean, and Europe.

Participants were invited using the member networks of the organisations listed above, augmented by 'snowballing' sampling techniques (allowing invitees to steer us towards or disseminate the details to others who they deemed eligible). ${ }^{20}$ We used a sampling matrix to ensure that our panel represented diversity in gender, age, residing country, location (rural or urban), role and discipline, and years of experience. Inclusion criteria were PHC practitioners, researchers or policy-makers residing and working in a LMIC. They required experience deemed relevant to provide opinions on regional or national research needs on the key area of PHC finances, that is, the way services are funded. Given a limited timeline and resources, the survey was only available in English and insufficient fluency in written English was an exclusion criterion. Our approach was to use advisory stakeholders (providers, researchers, policy-makers) who may identify gaps not identified by a literature review, by providing them with key categories and conducting an iterative review throughout the process. ${ }^{21}$

We had a timeline of 3 months to recruit the expert panel and conduct three survey rounds. The first round was qualitative with the aim of generating as many ideas as possible, whereas the subsequent rounds followed a modified Delphi method, providing anonymised summaries of responses to facilitate group convergence.

Participant recruitment took place in January 2018 via email. Responders whose details met study criteria were enrolled as panellists. The surveys were delivered using Qualtrics software, a web- based tool. Respondents had 1 week to complete each round. All rounds were anonymous. The Round 1 survey was piloted among WONCA's executive members, representing all global regions, prior to panel circulation to assess that it was comprehensible to non-native English speakers, and easy and quick to complete. ${ }^{22}$ Modifications were made in response to feedback.

To protect the identity of panellists, participant demographics were limited to residing region and country; rural or urban; age (range); gender; current role(s) (practitioner including type, academic, policy-maker), and years of experience. Ethical approval for the study was obtained from the University of Auckland Human Participants Ethics Committee.

In Round 1, participants were asked to generate research questions that addressed gaps in knowledge in PHC finance (such as payment systems, public/private funding, budgets, PHC spending). Extracted questions generated by the panellists were collated and coded into domains, categories and subcategories using a general inductive thematic approach. ${ }^{23}$ Categories included those already identified from existing frameworks, as well as de novo ones that arose from the data. Two researchers independently coded the first 25 respondent replies and Cicchetti-Allison kappa coefficients (a measure of interrater reliability) calculated to check for consistency in coding. Data were sorted by codes, collapsed and synthesised to a list of 31 questions. Similar questions from multiple participants were combined into representative questions for Round 2.

In Round 2, all enrolled participants were invited to rate each of the 31 questions on a four-point Likert scale for what they considered to be the level of importance for this topic to be researched in their country. The question lists were randomly presented to each participant to prevent response bias from the order of presentation. The participants' responses were used to calculate agreement indicated by mean score (larger mean demonstrated more agreement). Collated responses were ordered in degree of importance, and the top 16 research questions were selected for Round 3.

In Round 3, panellists were asked to prioritise the 16 research questions by dragging and dropping them into 
order of importance for their country. The question lists again were randomly presented. The highest-ranking questions for PHC financing were selected for the subsequent formulation of research implementation plans.

\section{Analyses}

We used a general inductive approach to thematic analysis for Round $1 .^{23}$ Statistical analyses were performed with SAS V.9.3 (SAS Institute, Cary, NC).

\section{Patient and public involvement'}

Patients were not involved in this study. The aim was to identify and prioritise the knowledge needs of PHC practitioners, researchers and policy-makers in LMIC. The study involved considerable input from, and co-design with, professionals from LMIC, but patient participation in this context was not appropriate.

\section{Scoping literature review}

The literature review was conducted to test whether there was already an LMIC literature base for each of the research questions generated by the panel or was this truly a gap in the PHC literature. A two-dimensional coding matrix was constructed based on the PHCPI conceptual framework and the dimensions of PHC financing identified through coding the questions generated in Round 1 of the panel. Some of the searches were conducted by two researchers independently to avoid researcher bias and check for coding consistency. ${ }^{24}$

Inclusion criteria were studies conducted in LMIC within the last 15 years in PHC or family practice with Medical Subject Headings or key terms pertaining to the questions of interest. Commentaries were excluded. Only covering a limited time period is an accepted technique for conducting rapid reviews. ${ }^{25}$ The studies were screened for relevance, and those not meeting the inclusion criteria were excluding initially by reviewing the title, second the abstract, and third the full paper if necessary.

The search was conducted in PubMed through Eppi-Reviewer-4 literature management software with shared review. The literature review was confined to research published in peer-reviewed journals. A two-dimensional coding matrix was constructed based on the PHCPI conceptual framework and the dimensions of PHC financing identified through coding the questions generated in Round 1 of the panel. It should be noted that we conducted 31 scoping reviews to determine whether the generated questions represented real gaps, but this was not a systematic review of the literature.

Using our matrix, selected articles relevant to the question were coded for both axes, and for filters to be added to the map. These consisted of a list of the global regions and a list of all LMIC countries.

\section{Gap map}

Our gap map shows the existing evidence and the spaces between. It is based on the generated questions of interest by our panellists, and our subsequent literature reviews to determine whether there is in fact existing evidence relating to these. It requires development of a framework of the interventions and outcomes of interest. ${ }^{25}$ In our case, we used the domains, categories and subcategories developed from the generated research questions to inform our conceptual framework, as well as the PHCPI conceptual framework.

Once all our selected articles were coded, the software providers at Eppi-Reviewer-4 generated our gap map for us, to enable visualisation of the 'bubbles' of available evidence and the evidence gaps related to the 31 research questions.

\section{Research implementation plans}

Panellists were invited to submit expressions of interest to prepare implementation plans for the top three questions. Researchers were selected based on their known track record in PHC research. Their submitted draft plans were used at a workshop run by members of the research team at the WONCA Europe conference in Krakow, Poland in May 2018. During the workshop, small groups of participants critiqued the plans and provided feedback, which was shared with those preparing the plans for their LMIC.

\section{RESULTS \\ Development of prioritised research questions}

There were 141 participants enrolled in the study based in 50 LMIC from all global regions. Africa had high representation including four low-income countries. Asia Pacific and the Eastern Mediterranean (ie, North Africa and the Middle East) were relatively under-represented. In all, $70(50 \%)$ completed Round 1 with a broad range of demographic characteristics. They were predominantly family physicians, many of whom were also researchers and/ or involved in policy-making. They had a range of experience as health professionals and as academics. We have described the panellists in detail in an earlier publication. $^{26}$

Independent coding of the first 25 survey responses showed a high degree of consistency with a Cicchetti-Allison kappa coefficient weight $\mathrm{I}=0 \cdot 6106$ (95\% CI 0.0 .3107 to 0.9105$) \mathrm{p}<0.0001$ (substantial agreement). In the final LMIC data set, 479 valid generated questions or responses were coded. Round 2 consisted of 31 questions on financing for rating.

In all, $84(60 \%)$ of the enrolled participants completed Round 2 (table 1). All 31 questions and the top 16 when ratings were summed are shown in table 1 .

Round 3, which ranked the questions in order of importance, was completed by $68(48 \%)$ of enrolled participants. One of the top ranked questions in our parallel organisation of PHC project ('How can the public and private sectors work more collaboratively to improve and integrate $\mathrm{PHC}$ coverage and prevent segmentation of the services?') was clearly more relevant to PHC organisation than finance; hence we moved it. The team subsequently 
Table 1 Research questions for financing rated for importance

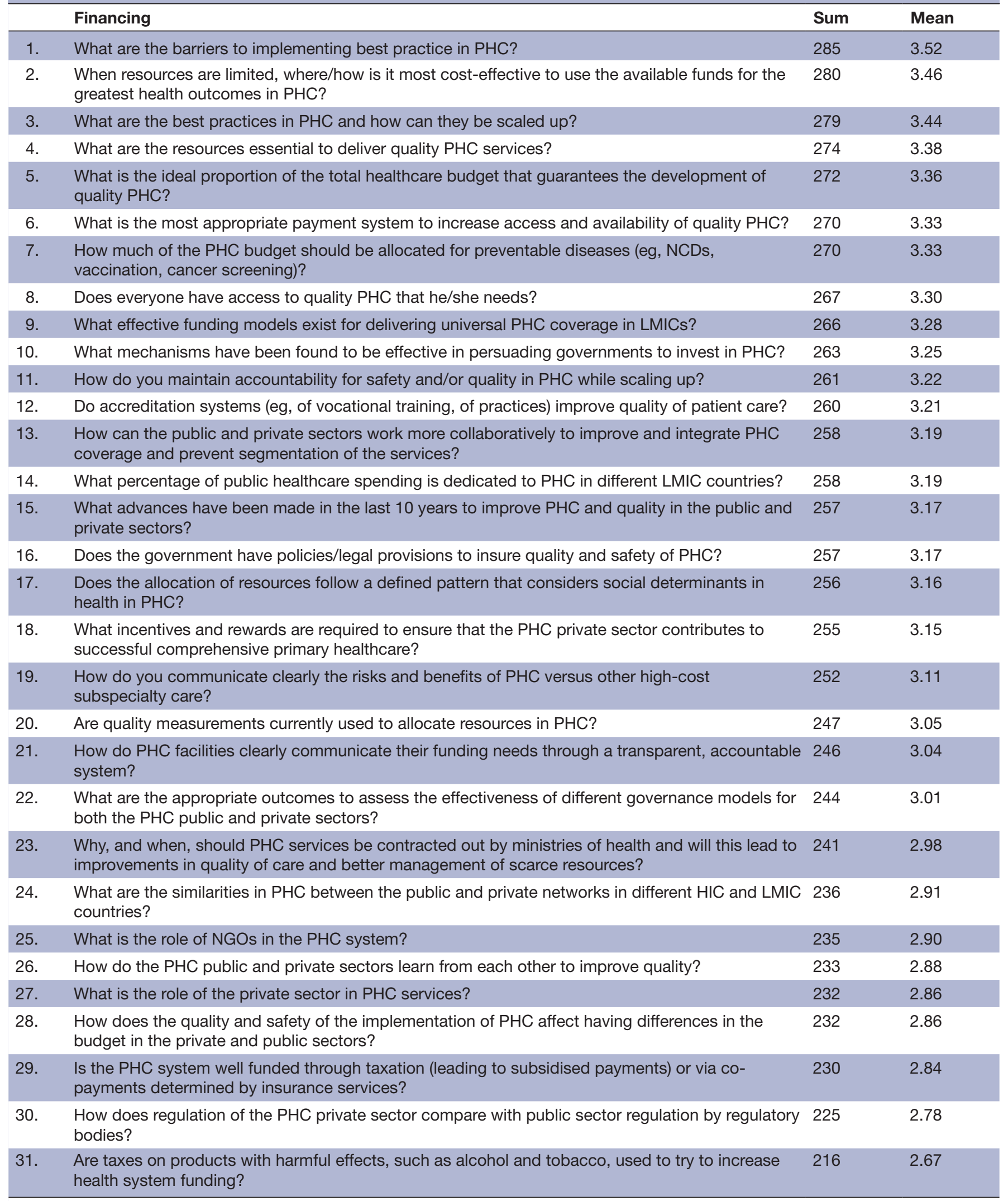

HIC, high-income country; LMICs, low- and middle-income countries; NCDs, noncommunicable diseases; NGOs, non-governmental organisations; PHC, primary healthcare. 


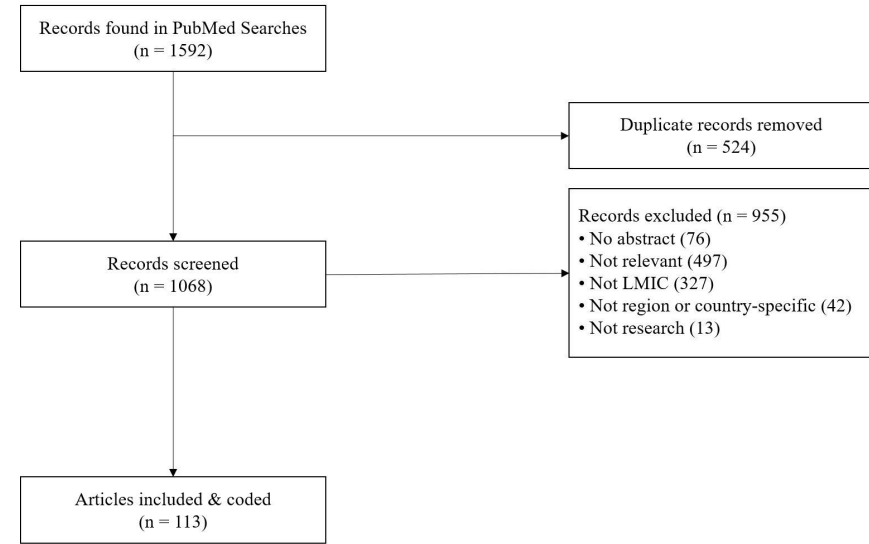

Figure 1 Flowchart of literature reviews. LMIC, low- and middle-income country.

discussed the general feasibility of the questions and moved some to higher priority.

The final top three ranked questions for the development of implementation plans are:

1. What is the most appropriate payment system to increase access and availability of quality PHC?

2. What mechanisms have been found to be effective in persuading governments to invest in PHC that might be implemented?

3. What is the ideal proportion of the total healthcare budget that guarantees the development of quality PHC?

\section{Literature review}

From 1592 records found, 113 met inclusion criteria (figure 1). See online appendix file for the reference list. Articles were coded according to the matrix for the two axes, and also coded for region and country. All regions of the world were represented, with the most studies in Africa (93), followed by Latin America and the Caribbean (60), Asia/Pacific (47), South Asia (32), Europe (18) and then the Eastern Mediterranean (13). See figure 2 for country-level distributions.

\section{Gap map}

A bubble gap map was generated through Eppi-Reviewer-4 to reveal a summary of existing evidence against a matrix of Primary Healthcare Performance Indicators currently

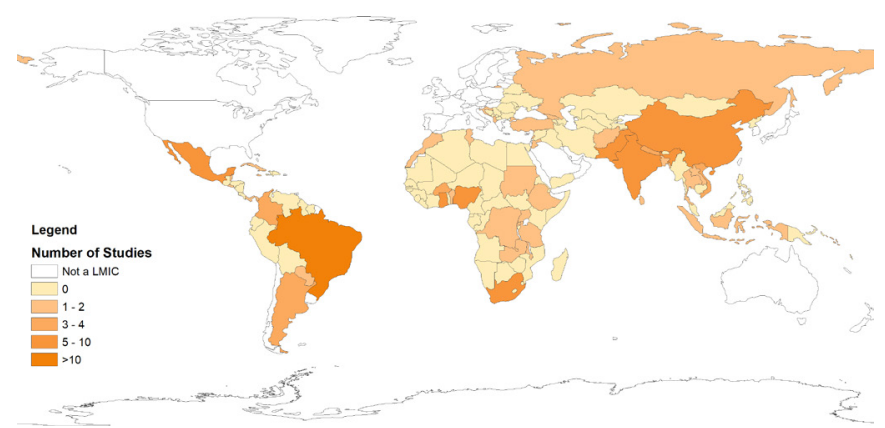

Figure 2 Number of studies from each LMIC. LMIC, lowand middle-income country.

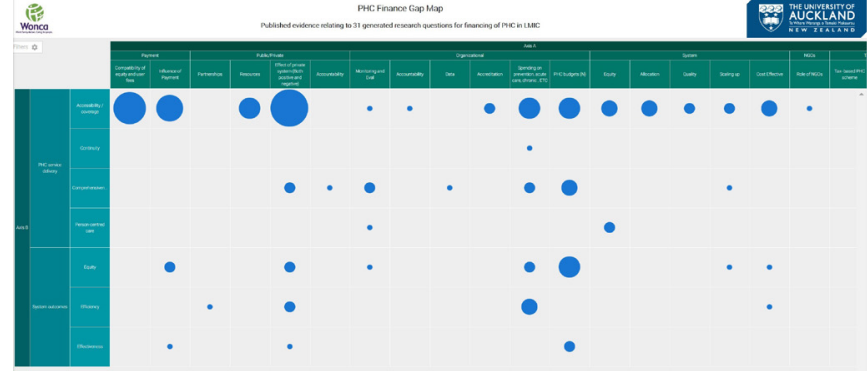

Figure 3 Static copy of gap map. PHC, primary healthcare.

being developed by the World Bank. A static version is shown in figure 3 . An interactive web-based map was also generated (Gap Map finance) which presents both heat-map and bubble-map versions, includes filters for LMIC and for global regions, and enables viewing of all studies in a cell by clicking on the bubble.

It is clear that there are significant gaps, and the questions generated by our panellists have not been previously answered. Country-specific implementation plans have been prepared for the first three questions (table 2).

\section{DISCUSSION}

\section{Summary of results}

The volume and breadth of LMIC participants, and their response rates across three rounds of question generation, rating and rankings was far beyond our expectations. Questions submitted in the first round produced many common themes, and the rating and ranking stages produced three questions-focused on payment and other incentives to provide equitable access to high-quality PHC; strategies to convince politicians to adequately support PHC; and the ideal levels of PHC financing as a proportion of total health spending. ${ }^{27}$

The literature review found accessibility and comprehensiveness were the predominant foci of LMIC research literature. The PHC financing literature review and research question priorities both emphasise access and continuity as LMIC priorities while the latter also adds research questions about PHC financing that are likely shared interests of developing countries. This makes sense for LMICs because their financing efforts are most likely aimed at increasing basic access and shifting to horizontal rather than vertical care delivery programmes. ${ }^{28}$ Outcome studies were heavily focused on equity issues-that is who can get what under what kind of financing package-perhaps because many LMIC have two-tiered systems. Several studies address financing schemes aimed at reducing disparities and influencing private providers to see publicly insured patients or reduce out-of-pocket costs. Few studies addressed continuity, effectiveness or person-centred care which are more common in HICs. Accessibility of PHC also shows up in two of the four questions generated by our study. Given the emphasis on 'people-centred' PHC in the WHO Astana Declaration, ${ }^{29}$ the related LMIC literature gap and research question prioritisation should raise questions about how WHO will incorporate LMIC priorities. 
Table 2 Country-specific questions developed for the top three prioritised questions

\begin{tabular}{|c|c|c|c|c|}
\hline Country & Research question & Aims & Methods & Teams \\
\hline Croatia & $\begin{array}{l}\text { What is the most } \\
\text { appropriate payment } \\
\text { system to increase } \\
\text { access, availability, } \\
\text { competency and } \\
\text { outcome indicators } \\
\text { of family medicine in } \\
\text { Croatia? }\end{array}$ & $\begin{array}{l}\text { 1. To assess the attitude and } \\
\text { knowledge of patients, } \\
\text { doctors (family medicine, } \\
\text { public health, hospital } \\
\text { doctors), directors of } \\
\text { PC centres, insurance } \\
\text { companies, local and state } \\
\text { politicians, non-government } \\
\text { associations about the role, } \\
\text { involvement and placement } \\
\text { of family medicine in the } \\
\text { health system. } \\
\text { 2. Develop proposed financing } \\
\text { plan for general practitioners }\end{array}$ & $\begin{array}{l}\text { Analysis of existing data and } \\
\text { comparative analysis of different } \\
\text { PHC payment systems in the world } \\
\text { Survey \& focus groups of target } \\
\text { stakeholders - patients, doctors, } \\
\text { directors of PC centres, insurance } \\
\text { companies, local \& state politicians, } \\
\text { non-government associations about } \\
\text { attitude \& knowledge of the role, } \\
\text { involvement \& placement of family } \\
\text { medicine in the health system } \\
\text { Development of proposal for general } \\
\text { practice financing based on these } \\
\text { results }\end{array}$ & $\begin{array}{l}\text { Dr Tanja Pekez- } \\
\text { Pavlisko (lead) } \\
\text { Dr Dinka Jurisic } \\
\text { Professor Maja Racic } \\
\text { Assistant Professor } \\
\text { Nemanja Rancic }\end{array}$ \\
\hline Kenya & $\begin{array}{l}\text { What mechanisms } \\
\text { have been found to be } \\
\text { effective in persuading } \\
\text { governments to invest } \\
\text { in PHC that might } \\
\text { be implemented in } \\
\text { Kenya? }\end{array}$ & $\begin{array}{l}\text { 1. To conduct grey literature } \\
\text { review to determine which } \\
\text { countries have invested } \\
\text { highly and those that have } \\
\text { not } \\
\text { 2. To conduct key informant } \\
\text { interviews with conveniently } \\
\text { selected representatives } \\
\text { from countries that have } \\
\text { invested highly in PHC and } \\
\text { those that have not. } \\
\text { 3. To develop a tool to use in } \\
\text { interviewing key Kenyan } \\
\text { stakeholders in health } \\
\text { services management }\end{array}$ & $\begin{array}{l}\text { Mixed method using both qualitative } \\
\text { and quantitative data } \\
\text { Review grey literature in PHC } \\
\text { investments globally and categorise } \\
\text { into those who have invested highly } \\
\text { and those who have not } \\
\text { Compare health cost per capita and } \\
\text { health indicators for two categories } \\
\text { Conduct key informant interviews } \\
\text { with conveniently selected } \\
\text { representatives from countries from } \\
\text { both categories } \\
\text { Use these data to develop a tool for } \\
\text { use in interviewing key stakeholders } \\
\text { in health services management in } \\
\text { Kenya }\end{array}$ & $\begin{array}{l}\text { Dr Patrick Chege (lead) } \\
\text { Dr Joseph Thigiti } \\
\text { Dr Ann Mwangi } \\
\text { Dr Joy Mugambi } \\
\text { Dr Bruce Dahlman } \\
\text { Dr Izaaq Odongo } \\
\text { Dr Jeremiah Laktabai } \\
\text { Edith Kabure }\end{array}$ \\
\hline Turkey & $\begin{array}{l}\text { What is the ideal } \\
\text { proportion of the total } \\
\text { healthcare budget } \\
\text { that guarantees the } \\
\text { development of quality } \\
\text { PHC in Turkey? }\end{array}$ & $\begin{array}{l}\text { 1. Describe how expenditure } \\
\text { items, trend of expenses } \\
\text { attributed to PHC and } \\
\text { financial policies of Turkish } \\
\text { healthcare budget differ from } \\
\text { other upper middle-income } \\
\text { countries having same GDP } \\
\text { 2. Determine the quality of } \\
\text { care provided in PHC } \\
\text { in Turkey, the disabling } \\
\text { financial barriers and rational } \\
\text { priorities that may enable } \\
\text { high-quality PC service } \\
\text { provision }\end{array}$ & $\begin{array}{l}\text { Review of existing policy } \\
\text { frameworks, strategic documents, } \\
\text { meeting/workshop reports, } \\
\text { medical news, statistical reports } \\
\text { and research papers providing } \\
\text { information about healthcare } \\
\text { system budget policies for Turkey \& } \\
\text { comparison countries } \\
\text { Survey of physicians \& patients } \\
\text { using established questions to } \\
\text { assess PHC quality \& functions } \\
\text { Longitudinal, direct observation of } \\
\text { PHC practices to identify financial } \\
\text { barriers to care } \\
\text { Key informant interviews (policy- } \\
\text { makers, economists, academics } \\
\text { \& health directors) about financial } \\
\text { policies for PHC } \\
\text { Delphi panel for reaching consensus } \\
\text { about priority areas for achieving } \\
\text { high-quality PHC services } \\
\text { Summative analysis to identify } \\
\text { proportion of total healthcare budget } \\
\text { that guarantees development of } \\
\text { quality PHC in Turkey and achieving } \\
\text { key WHO/UN health targets }\end{array}$ & $\begin{array}{l}\text { Professor Akman (lead) } \\
\text { Professor Sibel Sakarya } \\
\text { Professor Serap Çifçili } \\
\text { Professor Pemra Cöbek } \\
\text { Ünalan } \\
\text { Professor Bulent Kılıç } \\
\text { Dr Hülya Akan } \\
\text { Emrah Kırımlı } \\
\text { Professor Peter } \\
\text { Groenewegen } \\
\text { Professor Kaan Sözmen } \\
\text { Tino Marti }\end{array}$ \\
\hline
\end{tabular}

GDP, gross domestic product; PC, primary care; $\mathrm{PHC}$, primary healthcare.

The research questions generated have a strong focus on the position of PHC in the health system, and the potential need to establish normative financing thresholds for PC and the political strategies to make this possible. All the generated questions are likely have relevance around the world, but could be structured for further research in LMIC specifically. Workforce incentivisation and stabilisation (Q3) are likely to be general priorities around the 
world in both HIC and LMIC. They resonate with work of OECD, the World Bank, and WHO.

\section{Strengths of the study}

A strength of this research is the size and composition of our panel of 141 from LMIC recruited over 2 weeks. This demonstrates a strong interest in the PHC sector in LMIC for research into health service delivery and systems to inform practice and policy.

We have consistently used a bottom-up approach. Our literature review was undertaken from the perspective of the stakeholders, searching for possible evidence already available for the prioritised questions that they had generated. We have used researchers in LMIC who know their own contexts to develop implementation plans relevant to their own country or region's needs and resources. Bottom-up input is generative and more likely to lead to research acceptable to front-line practices. It may also offer policy-makers policy-relevant options that translate into effective change. This study therefore contributes to potential reforms on the most urgent needs in local contexts.

We used the same panel for both organisation and financing because the development of effective PHC organisation and models of care cannot be isolated from mechanisms of funding, and these key areas go hand-inhand. A sister paper presents the findings for the former, but evidence from WONCA comparative studies on PHC policy implementation, ${ }^{30-33}$ highlights the need for an integrated coherent approach.

The large number of initial research questions and significant gaps in LMIC literature suggest a broader evidence gap in LMIC, but our process highlights bottom-up prioritisation. In this effort, our methods met the Guidance on Conducting and Reporting Delphi Studies recommendations for selecting the panel, piloting the survey, conducting the rounds, maintaining anonymity and developing consensus. ${ }^{34}$ WONCA's rich network of PHC relationships made it possible to recruit a robust response within tight time constraints. It also made it possible to recruit LMIC leaders for the development of derivative study proposals.

A further strength was the robust qualitative approach which achieved a high degree of inter-rater coding reliability and which supported an iterative Delphi approach which produced prioritised research questions.

\section{Limits of the study}

We had insufficient time and resources to use translation services for our Qualtric surveys. This meant that we required our panellists to be fluent in English, and hence limited potential participation. The countries of enrolled African participants are mostly Anglophone. Furthermore, our literature searches were conducted using PubMed and restricted to English language publications.

Most panellists were family physicians whose experience and issues of concern may differ from those of other PHC professionals such as nurses or community health workers, and from many policy-makers. It is very likely that the predominance of respondents focused on PC and not on the broader topic of PHC. Anecdotally, discussions with PC researchers from LMIC at the WONCA meeting in Seoul immediately preceding Astana, offered general concerns that PHC research and financing efforts in mainly LMIC differentially favour public health over PC. These discussions contribute to our belief that our findings likely relate more to PC than PHC. Time constraints limited our ability to disseminate our panel invitation widely through other networks.

We were unable to conduct the literature reviews as robustly as we would have liked, given the time restraint. Studies were mostly screened on based on abstract, those lacking an abstract were excluded, and there was an English language bias. It may also have been affected by lack of differentiation in current literature between PHC and PC. The themes derived from our search suggest that PC dominates published LMIC research. However, clearly the evidence gap is very real, and there is no robust body of literature that answers our proposed priority questions.

\section{CONCLUSION}

Practitioners, academics and policy-makers from LMIC prioritised three questions about PC financing that focused on general adequacy of PC funding, evidence for convincing policy-makers about adequate PC funding, funding to support adequate access to PC, and funding to support equitable PHC workforce distribution. LMIC literature review reinforced the focus on PHC accessibility and equity. The first two research questions may not be specific to LMIC, but the latter two, like the literature review, highlight particular needs of LMIC. Both foci inform needed and related research efforts in LMIC, but research funders should also pay attention to the more generalisable questions to ensure international relevance and comparability. Finally, there is a clear need to differentiate the entities of PHC and PC, both in international discussions and in research. The different terminology around PC and PHC impacts any study on this issue, including ours. We recommend consistent use of these terms, something that has become even more important after Astana.

\footnotetext{
Author affiliations

${ }^{1}$ Department of General practice and Primary Health Care, Faculty of Medical and Health Sciences, University of Auckland, Auckland, New Zealand

${ }^{2}$ Robert Graham Center Policy Studies in Family Medicine \& Primary Care, Washington, DC, USA

${ }^{3}$ Department of Primary Care, University of East Anglia Norwich Medical School, Norwich, , UK

${ }^{4}$ Department of Family and Community Medicine, University of Toronto, Toronto, Ontario, Canada

${ }^{5}$ Southgate Institute for Health, Society and Equity, Flinders University, Adelaide, South Australia, Australia

${ }^{6}$ Research and Policy Department, the American Board of Family Medicine, Lexington, Kentucky, USA

${ }^{7}$ Radboud Institute of Health Research, Department Primary and Community Care, Radboud Universiteit Nijmegen, Nijmegen, The Netherlands
} 
${ }^{8}$ Department of Health Services Research and Policy, Australian National University, Acton, Australian Capital Territory, Australia

Acknowledgements We gratefully acknowledge Drs Asaf Bitton, Director and Lisa Hirschhorn, Senior Advisor of Primary Health Care, Ariadne Labs for their support and assistance with this study. We also wish to acknowledge David Peiris and his team at the George Institute for Global Health whose work informed our coding matrix, and to thank them for sharing their material with us and recommending use of Eppi-Reviewer 4. The bid for the work described here was made with the agreement of WONCA World Executive. Members Dr Henry Lawson, Regional President for Africa; Professor Kanu Bala, Regional president for South Asia, and Dr Inez Padula, regional President for South America, supported the original bid. We also wish to acknowledge the lead researchers of the three implementation plans and their teams: Dr Tanja Pekez-Pavlisko, Primary Care Center Kutina, Croatia; Dr Patrick Chege, Family Medicine, College of Health Sciences Moi University, Nairobi, Kenya, and Assoc Prof Mehmet Akman, Department of Family Medicine, Marmara University, Istanbul, Turkey.

Contributors FG Led the proposal, study design and research implementation. Conducted qualitative analysis, oversaw other analyses, drafted initial paper and revised. $A B$ Involved in developing the proposal on which this article is based, is on the core project team, helped advise on methods development and contributed to consecutive versions of the article. MC Conducted qualitative data analysis, refined qualitative coding process and edited publication documents. RF Made substantial contributions to study design, data collection, qualitative and quantitative data analyses, and to the draft and critical revision of the manuscript. AH Involved in the bid for the work on which this article is based, on the core project team, input to methods development and commented on consecutive versions of the article. MK Involved in the bid for the work on which this article is based, is on the core project team, had input to all versions of the article. RP Involved in developing the proposal on which this article is based, is on the core project team, helped advise on methods development and contributed to consecutive versions of the article. KR participated in initial discussions about the project and in two teleconferences, provided input into the documents. CvW Involved in the bid for the work on which this article is based, on the core project team, had input to all versions of the article.

Funding This publication is based on research funded by Ariadne Labs through Brigham and Women's Hospital, which is the recipient of a Bill \& Melinda Gates Foundation grant. The findings and conclusions contained within are those of the authors and do not necessarily reflect positions or policies of the Bill \& Melinda Gates Foundation.

Competing interests None declared.

Provenance and peer review Not commissioned; externally peer reviewed.

Data sharing statement Data are available upon reasonable request. All data relevant to the study are included in the article or uploaded as supplementary information.

Open access This is an open access article distributed in accordance with the Creative Commons Attribution Non Commercial (CC BY-NC 4.0) license, which permits others to distribute, remix, adapt, build upon this work non-commercially, and license their derivative works on different terms, provided the original work is properly cited, appropriate credit is given, any changes made indicated, and the use is non-commercial. See: http://creativecommons.org/licenses/by-nc/4.0

\section{REFERENCES}

1. International Conference on Primary Health Care. Declaration of Alma-Ata. Alma-Ata, USSR: WHO, 1978.

2. Commonwealth Fund. Primary care: our first line of defense. New York: Commonwealth Fund, 2013.

3. European Forum for Primary Care. EFPC at a glance, 2017. Available: http://www.euprimarycare.org/about/efpc-glance

4. Goodwin N, Dixon A, Poole T, et al. Improving the quality of care in general practice Report of an independent inquiry commissioned by The King's Fund. London: The King's fund, 2011.

5. Starfield B. Measuring the attainment of primary care. Academic Medicine 1979;54:361-9.

6. World Health Organization. The World Health Report 2008: Primary Health Care - Now More Than Ever. Geneva: World Health Organization, 2008.

7. Marmot M. The health gap: the challenge of an unequal world. The Lancet 2015;386:2442-4.
8. Organization for Economic Cooperation and Development, Organization for Economic Cooperation and Development. Measuring primary spending and efficiency. Paper presented at: Joint Session of Health Accounts Experts and Health Data National Correspondents; October 4, 2016, Paris, France, 2016.

9. World Health Organization, Tarimo E, Webster E. Primary health care concepts and challenges in a changing world: Alma-Ata revisited. Geneva: WHO, 1994.

10. World Health Assembly. Primary health care, including health system strengthening. Geneva 22nd World Health Assembly, WHO; 2009.

11. Labonté R, Pooyak S, Baum F, et al. Implementation, effectiveness and political context of comprehensive primary health care: preliminary findings of a global literature review. Aust $J$ Prim Health 2008;14:58-67.

12. Beasley JW, Starfield B, van Weel C, et al. Global health and primary care research. J Am Board Fam Med 2007;20:518-26.

13. Rosser WW, van Weel C. Research in family/general practice is essential for improving health globally. Ann Fam Med 2004;2 Suppl 2(suppl_2):S2-S4.

14. OECD. STAT. OECD health statistics: Health expenditure and financing, 2018. Available: https://stats.oecd.org/index.aspx? DataSetCode=SHA [Accessed 2 Jun, 2018].

15. Whyte W. Participatory action research. Vol 123. Thousand Oaks, CA: Sage Publications, 1991.

16. Tindana PO, Singh JA, Tracy CS, et al. Grand challenges in global health: community engagement in research in developing countries. PLoS Med 2007;4:e273.

17. Delbanco T, Berwick DM, Boufford JI, et al. Healthcare in a land called PeoplePower: nothing about me without me. Health Expect 2001;4:144-50.

18. Sinha IP, Smyth RL, Williamson PR. Using the Delphi technique to determine which outcomes to measure in clinical trials: recommendations for the future based on a systematic review of existing studies. PLoS Med 2011;8:e1000393.

19. World Bank Group. List of economies, 2017. Available: https:// datahelpdesk.worldbank.org/knowledgebase/articles/906519-worldbank-country-and-lending-groups [Accessed 18 Mar 2018].

20. Sadler GR, Lee H-C, Lim RS-H, et al. Recruitment of hard-to-reach population subgroups via adaptations of the Snowball sampling strategy. Nurs Health Sci 2010;12:369-74.

21. Carey $T$, Yon A, Beadles $C$, Wines $R$. Prioritizing future research through examination of research gaps in systematic reviews Cecil $\mathrm{G}$ Sheps center for health services research University of North Carolina; 2012

22. Hsu C, Sandford B. Minimizing non-response in the Delphi process: how to respond to non-response. PARE Online 2007;12.

23. Thomas DR. A general inductive approach for analyzing qualitative evaluation data. Am J Eval 2006;27:237-46.

24. Higgins J, Lasserson T, Chandler J, et al. Methodological expectations of Cochrane intervention reviews (MECIR): standards for the conduct and reporting of new Cochrane intervention reviews, reporting of protocols and the planning, conduct and reporting of updates. Cochrane 2018.

25. Snilstveit B, Vojtkova M, Bhavsar A, et al. Evidence gap maps: a tool for promoting evidence-informed policy and prioritizing future research. Washington DC: Independent Evaluation Group, Public Sector Evaluation Department, The World Bank, 2013.

26. Goodyear-Smith F, Bazemore A, Coffman M, et al. Primary care research priorities in Low-and middle-income countries. Ann Fam Med 2019;17:31-5.

27. Organisation for Economic Co-operation and Development. Measuring primary spending and efficiency. Joint session of health accounts Experts and health data national Correspondents. Paris, France, 2016.

28. Shaw RP, Wang $H$, Kress $D$, et al. Donor and domestic financing of primary health care in low income countries. Health Systems \& Reform 2015;1:72-88.

29. World Health Organization. Astana Declarartion: from Alma-Ata towards universal health coverage and the sustainable development goals. Astana, Kazakhstan: Global Conference on Primary Health Care, 2018.

30. van Weel C, Kassai R. Expanding primary care in South and east Asia. BMJ 2017;356.

31. van Weel C, Kassai R, Qidwai W, et al. Primary healthcare policy implementation in South Asia. BMJ Glob Health 2016;1:e000057

32. van Weel C, Kassai R, Tsoi GW, et al. Evolving health policy for primary care in the Asia Pacific region. $\mathrm{Br} J$ Gen Pract 2016;66:e451-3.

33. van Weel C, Turnbull D, Ramirez J, et al. Supporting health reform in Mexico: experiences and suggestions from an International 
Primary health care conference. The Annals of Family Medicine 2016;14:279-80

34. Jünger S, Payne SA, Brine J, et al. Guidance on conducting and reporting Delphi studies (CREDES) in palliative care: recommendations based on a methodological systematic review. Palliat Med 2017;31:684-706. 